\title{
Qualitative Assessment of Worker Productivity and Experience in Office Environments
}

\section{Context}

This project is a study on the building impact of occupant's productivity and wellbeing in an office environment. Presented through an office case study, the work takes part of a larger pre- and post-move study carried out over the course of a year. The study collects, analyses, and compares numerous sources of data in a pre- and post-move study: 1 ) environmental (2) ontine qualitative surveys of user comfort relative qualitative in the office 3) comfort relative to location in the office 3 ) an architectura 1 assessment of the spaces in the office. The collection of both pre- and post-move data is intended to allow findings to be compared to understand the impacts of environmental design on worker productivity and building performance and address the challenges in conducting successful pre- and post-move assessments.

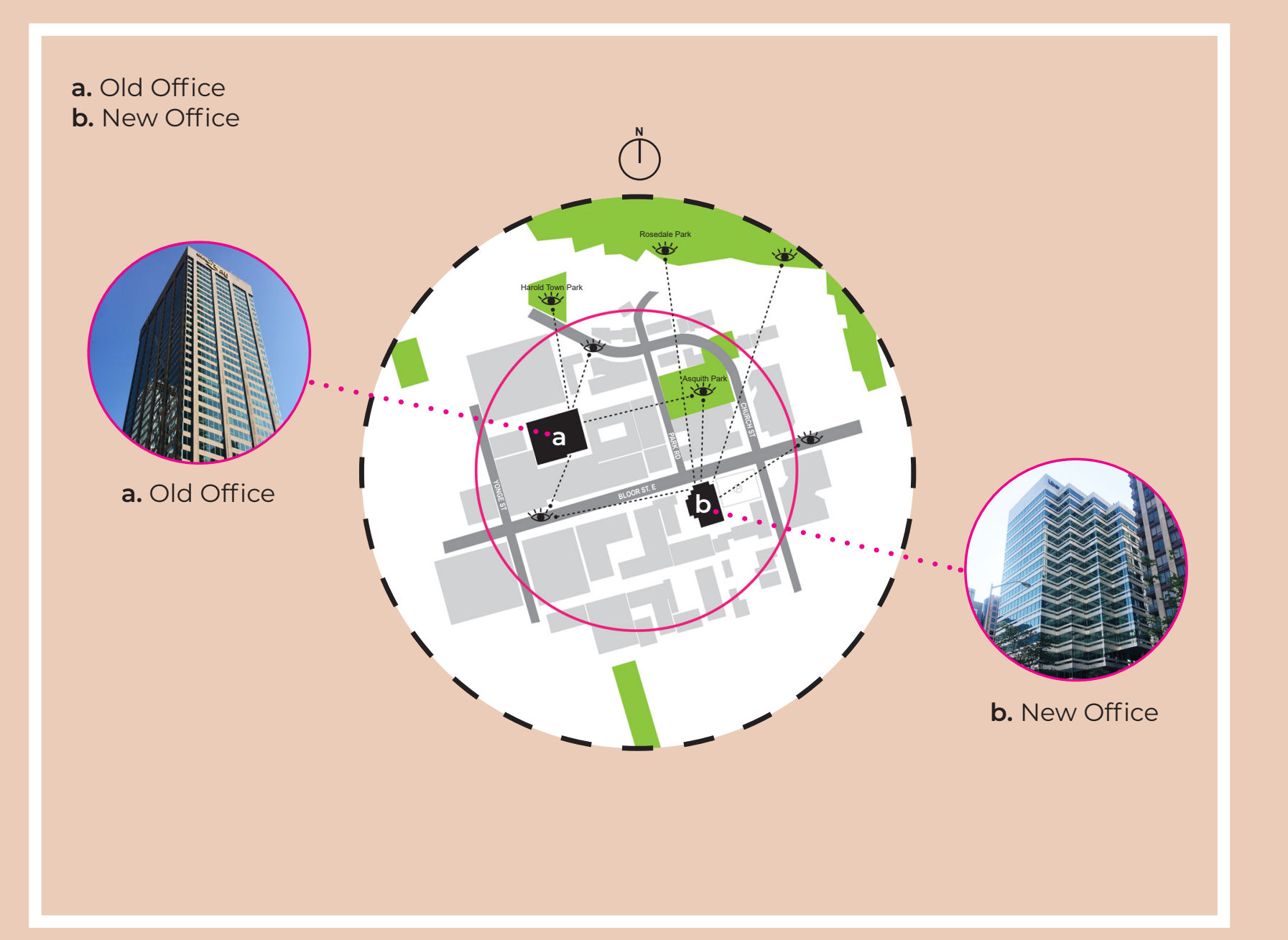

\section{Methodology}

Data Collection

when studying the relationship between occupant experience and building performance, it is imperative to collect both quantitative and qualitative data. Quantitative data is typically more measurable through the use of various building technologies. In this case, sensors were bu light, temperature, humidity, pressure, co2, light, temperature, humidity, pressure, c02, air quality, sound and proxinity. The sensors were placed throughout each office for month at a time while recording numbers on the SD cards. Collecting qualitative data can be more challenging. An online occupant survey was formulated to gain insights into how people working in the offices rate their comfort and productivity based on their location in the space.

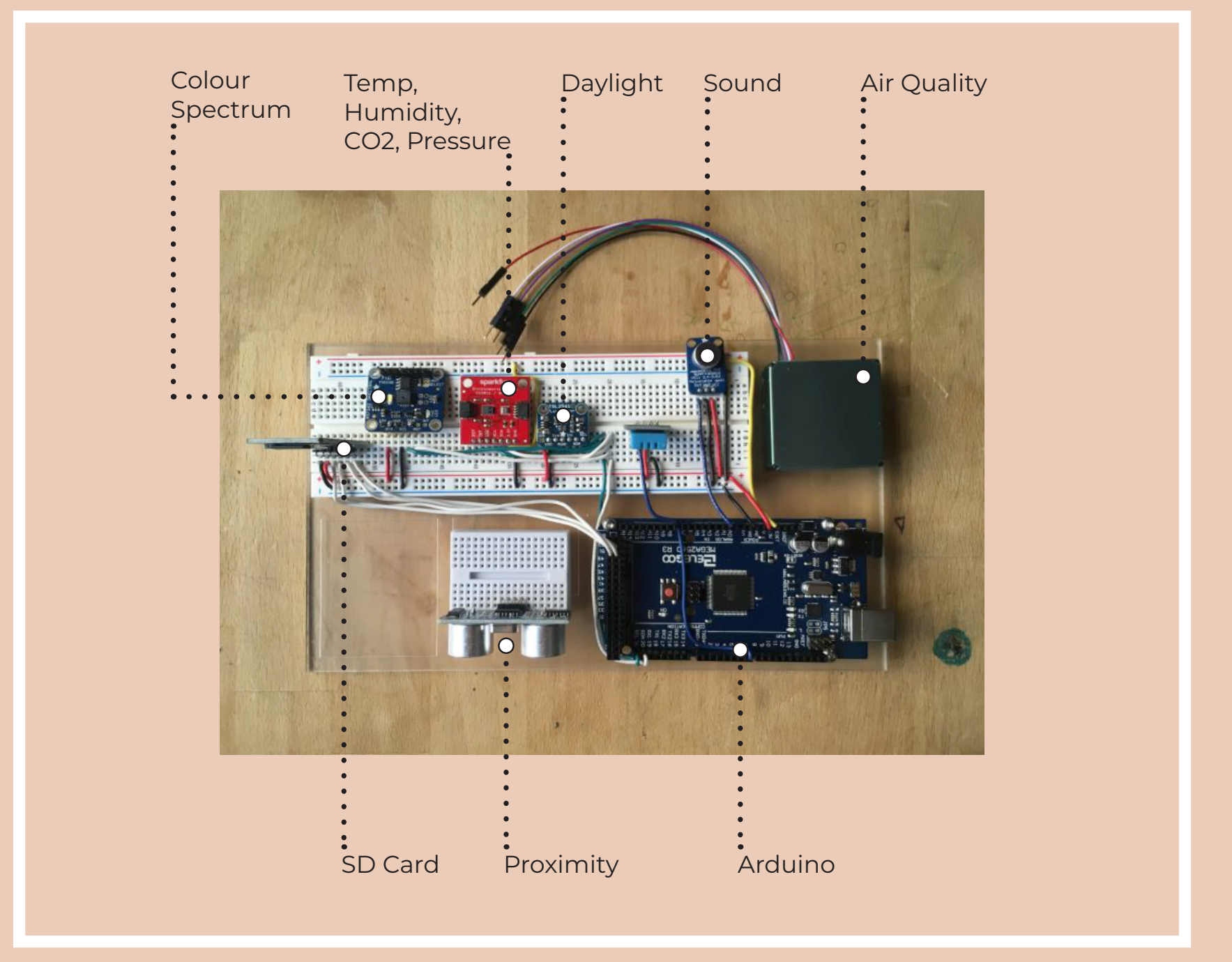

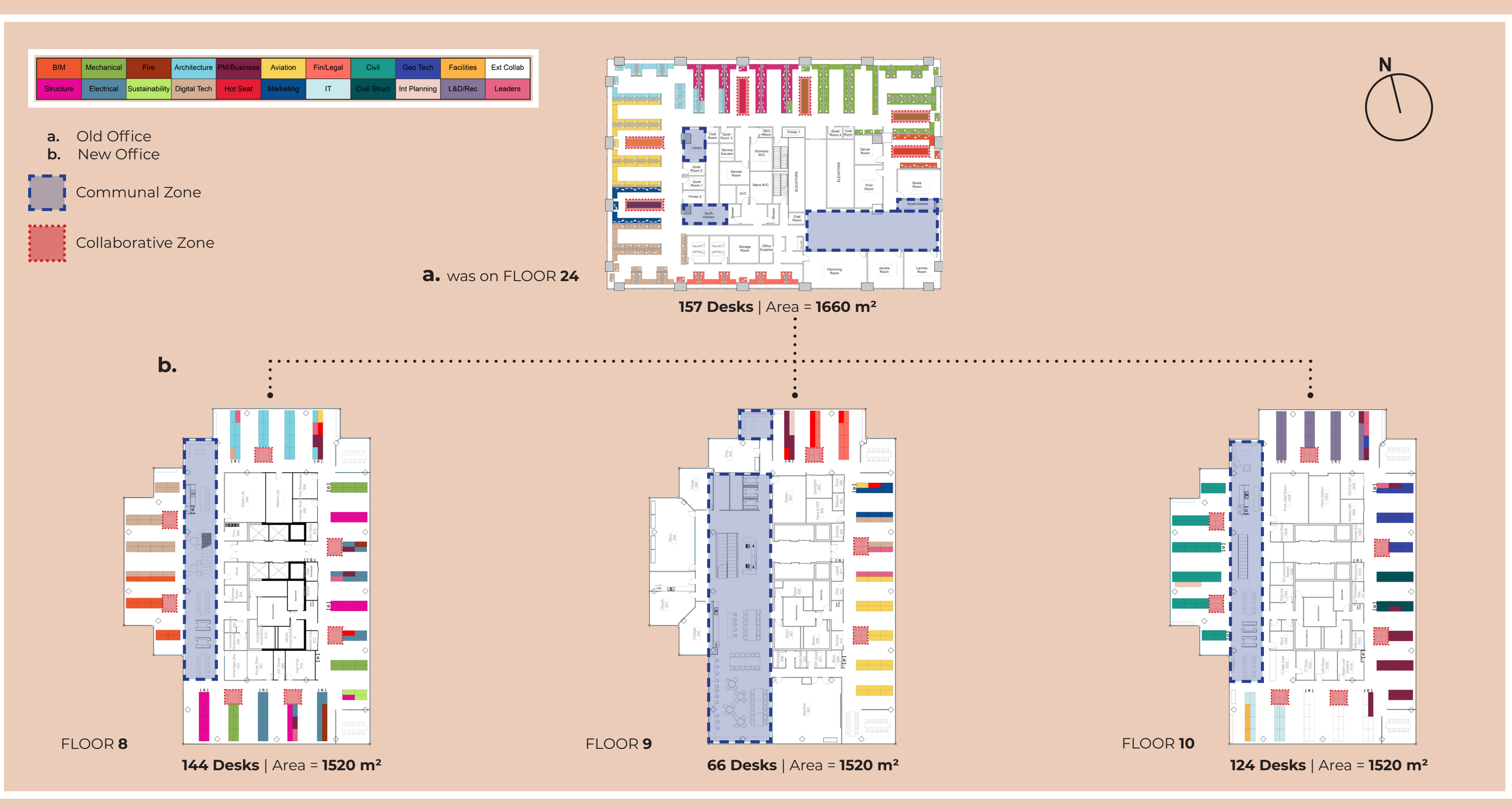

\section{Connection to Post-Occupancy Evaluations}

Post occupancy Evaluations (POES) are mportant tools to understand various aspects of how a building performs including how it meets the functional requirements, social and psychological performance and visual quality and satisfaction ${ }^{1}$. The issue today, is that although POES are being completed more frequently, very few are published. As each project varies in space, typology, etc. it creates challenges in formulating an overall standard for POES. Ho independent POE for a building.

\section{Architectural Assessment}

Based on a pre-determined criteria, the architectural assessment consisted of a thorough 3-hour walkthrough and documentation of the old and new office. Factors being observed included: thermal comfort, natural and artificial light, noise, layout, privacy, individual and group workspaces, integration of departments, degree of personalization, plants, sizes of workspaces, clutter, storage, use of blinds and views to understand the occupants' office environment and how all these factors impact their production and mental factors impact their production and mental

1 Preiser W.F.E and Schramm, U. (19997) "Building Performance Evaluation" in Watson D et al
(Eds) Time Saver Standards, ,th ed. MCCGrow-Will, New York, NY.

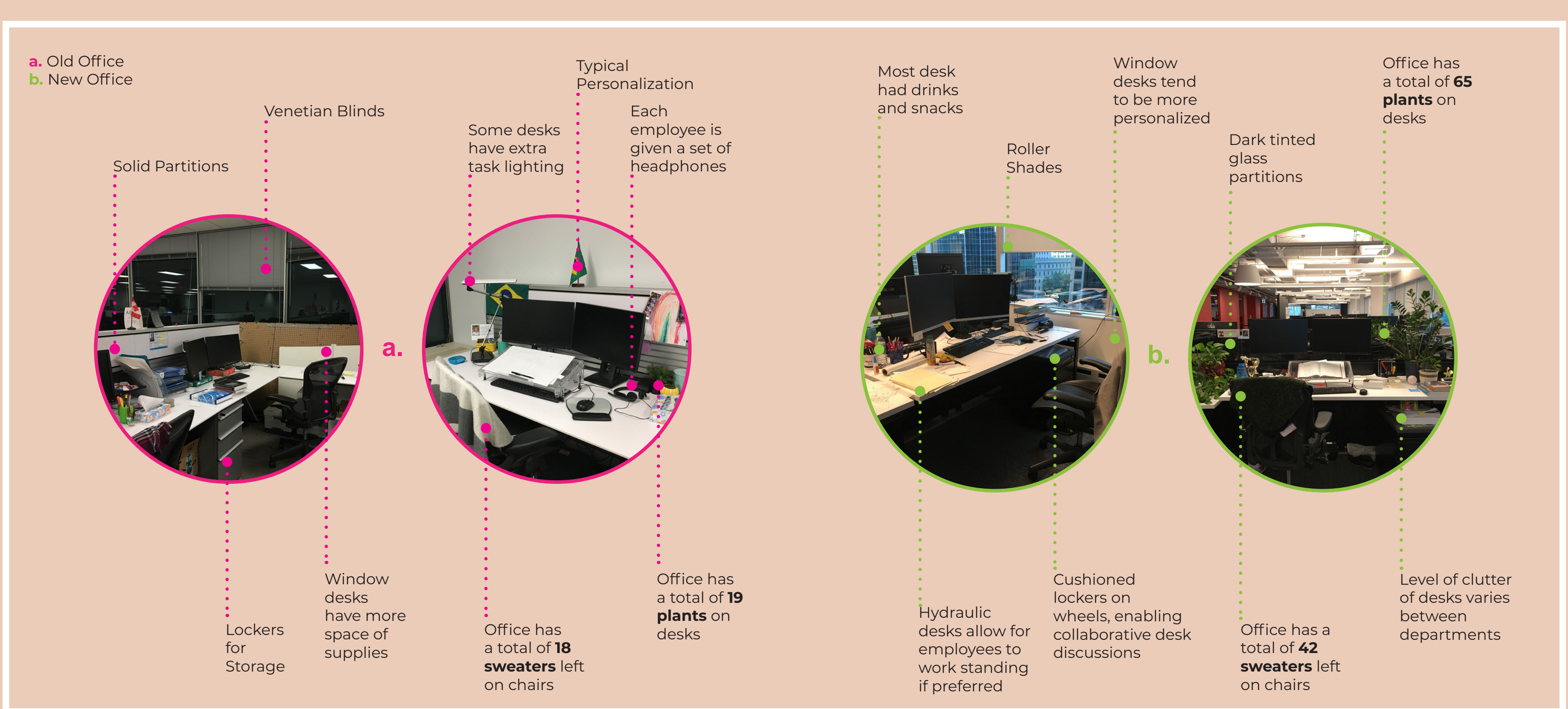

\section{Discussion}

Various challenges arose from the comparison of the two spaces because very little between the offices was directly comparable. The new office expanded from one to three floors, more than doubling the number of departments. The new office moved to a new location, receiving new office moved to a new location, receiving different views and a new overal1 layout. The space features coloured themes on each floor,
more social and communal spaces, increased mobility and individual desks that were on hydraulics to enable standing while working. The office provides a variety of collaborative zones, encouraging the occupants to move around.

\section{Conclusion}

In doing this project, many challenges arose which provided a strong insight on how to better design these types of assessments. when collecting data, the placement of the sensors, along with their quality performance is imperative. Furthermore, developing as many comparable criteria as possible to ensure the pre- and post-move as possible to ensure the pre- and post-move evaluations can be understood in parallel. The architectural assessment was a strong method for collecting qualitative data which normally is not considered. It helped and the results from the occupant survey. 